\title{
Investigation of the Learning Strategies of Pedagogical Formation Certificate Program Students in Terms of Some Variables
}

\author{
Harun Şahin ${ }^{1} \&$ Muhammed Ali Özkan ${ }^{2}$ \\ ${ }^{1}$ Faculty of Education, Akdeniz University, Antalya, Turkey \\ ${ }^{2}$ Information Technologies Teacher, Konya, Turkey \\ Correspondence: Harun Şahin, Faculty of Education, Akdeniz University, Antalya, Turkey
}

Received: October 27, 2019

Accepted: November 29, 2019

Online Published: February 17, 2020

doi:10.5539/ies.v13n3p18

URL: https://doi.org/10.5539/ies.v13n3p18

\begin{abstract}
The purpose of the current study is to investigate the use of learning strategies by students enrolled at the education faculty pedagogical formation program in their education life in relation to some variables such as gender, age, mother and father's education level and graduated undergraduate program. The study group of the current research is comprised of a total of 217 students attending the pedagogical formation certificate program in the Education Faculty of Burdur Mehmet Akif Ersoy University in the 2015-2016 academic year. In order to determine the students' learning strategies, the 32-item Learning Strategies Scale developed by Açıkgöz (1996) and revised by Güvenç (2009) was used. In the analysis of the collected data, SPSS 24 program package was employed and frequencies, percentages, arithmetic means, t-test ve Kruskal Wallis test were used. It was concluded that the students' learning strategies do not vary significantly depending on gender, age, mother and father's education level and the undergraduate program they graduated from.
\end{abstract}

Keywords: learning, learning strategies, pedagogical formation

\section{Introduction}

With the advent of the 21st century, there is a greater need for students who can take most of the responsibility for their own learning so that they can organize their own learning to be more successful and have a better standing in the world where lifelong learning is gaining greater importance and developments in science and technology and social change take place rapidly (Sucuoğlu, 2003). In addition, it can be said that the rapidly increasing need for information in social life necessitates changes in the education programs of schools from primary education to higher education all over the world.

In order to meet the qualified human needs of the information society, educating individuals who are learning to learn should be the primary objective of the education system. In this respect, in educational programs, it should be aimed to impart more advanced knowledge to students in such a way as to enable them not only to accumulate knowledge but also to use and produce it as required by the age of information. However, in order for this to be achieved in schools, students need to have effective learning competences (Özer, 2002).

In order to improve the quality of student learning, a better understanding of how student learning occurs should be developed (Beyaztaş \& Senemoğlu, 2015). Given the fact that the knowledge to be mastered is increasing exponentially, learning by using certain strategies has become a necessity (Vural, 2011). Individuals living in the information age need to know the ways of having access to information and how to use this information. This process, which can be described as learning to learn, can be expressed as the student's taking the responsibility for his/her learning and deciding which activities he/she should be engaged in to fulfil this responsibility.

In order for students to learn to learn, they need strategies to activate their own learning characteristics (Güven, 2004). Learning difficulties encountered while learning are the most frequently mentioned problems by students. While some students cannot study though they want to, some cannot learn enough even if they have worked for long periods. As a result of both the increasing intensity of such problems and the developments in the field of cognitive psychology, the idea that the student is an effective participant he/she can organize his/her own learning process has become dominant and thus the importance of learning strategies in the field of education has increased (Açikgöz, 2007). Tezbaşaran (1997) also emphasizes that the efficiency of teaching will increase to the extent that it can dissuade passive learners from being passive, mobilize and enable them to participate in the interaction 
process.

The teacher's efforts alone may not be enough for learning to take place. The real learning can occur only when the student personally involved in the process of learning. The student's involvement in the act of learning depends on how well he/she knows the learning strategies and how effectively he/she can use them (Tay \& Yangin, 2008). While strategy is generally viewed as the way to be followed to achieve something or the implementation of a plan developed to achieve a goal (Açıkgöz, 2007), learning strategies are defined as behaviours and thoughts used by the student during learning to influence the student's coding process (Senemoğlu, 2005). In other words, learning strategies are a set of approaches that students use to perform academic tasks or improve their social skills in the learning process (Şimşek, 2006).

Learning theories have been developed as a result of research focusing on how learning occurs, how an individual receives, processes and stores information. One of these theories is the "Information Processing Theory", which views learning as a mental process. The information processing theory describes the learning process as the reception of the stimulus, making sense of it, its storage, its recalling for use, and its transformation into behaviour. This theory argues that for learning to occur, the individual should also participate in the learning process and make some efforts (Çalışkan \& Sümbül, 2011).

Explaining learning strategies in relation to learning processes in accordance with the information processing theory, Gagné divided these strategies into five groups. These are Attention Strategies, Strategies that Improve Storage in the Short-Term Memory, Strategies that Improve Coding, Strategies that Facilitate Recall, Monitoring Strategies (Tay \& Yaygin, 2008).

Many different classifications have been made regarding learning strategies. Although all of these classifications have been made according to the information processing model, it is difficult to say that there is a consensus on the classification of learning strategies. The most comprehensive classification widely used today and providing the basis for many studies was made by Weinstein and Mayer (1986, as cited in Erdem, 2005).

According to Weinstein and Mayer (1983, as cited in Efe, Sağırlı, \& Ünlü, 2009), these strategies are rehearsal strategies, elaboration strategies, organizational strategies, comprehension monitoring strategies and affective strategies (Efe et al., 2009). Erden (1997) divided learning strategies into two groups as strategies used in learning simple and complex information, and then created three sub-classifications under each group as rehearsal and revision, organization and elaboration. Senemoğlu (2005) discussed learning strategies in terms of internal processes and explained them in six groups: attention strategies, strategies that enhance storage in the short term memory, strategies that improve elaboration (coding), strategies that foster recall, motivation enhancing strategies and executive cognitive strategies.

It has been demonstrated by many studies conducted by educational researchers that regardless of the learning strategies classification adopted, learning strategies increase the academic achievement of students and enable them to achieve better and lasting learning when they are used properly and effectively (Sönmez, Gündüz, \& Selvi, 2015). Cognitive learning strategies and techniques relate to how the subject is explained to the learner and how the learner processes information. The current study is based on the classification of learning strategies according to the information processing model. The current study is built on the strategy grouping defined by Aç1kgöz (2007) in five sub-dimensions. These are named as processing, metacognitive, organization, concentration and memorization.

As stated by Karakış and Çelenk (2007), in order for students to be able to use their learning strategies effectively, their learning strategies should be determined first. Measurement tools commonly used in the determination of the learning strategies of students are the scales for determining learning strategies.

In the literature, there are scales used for the determination of the learning strategies of students from different levels of schooling. These learning strategies scales are the scales mostly used in research about the learning strategies used by elementary, secondary, high school and higher education students (Çelik, 2016; Şahin \& Uyar, 2013; Toy, 2007; Yavuzaslan, 2017; Yücel, 2012). No special scale used in research conducted on pedagogical formation students has been found. In this respect, it is important and necessary to determine the learning strategies of pedagogical formation students. As a matter of fact, teachers who will impart learning skills to their students and enable them to use learning strategies effectively must have skills necessary to learn how to learn and be able to use learning strategies. It is thought that if teachers are aware of the importance of learning strategies, then they can transfer these strategies to their students. Thus, learning strategies gain greater importance. It is also believed that pre-service teachers' having knowledge of how to use learning strategies will help them both enhance their own learning and teach their prospective students how to use learning strategies at an early age. 
The purpose of the current study is to determine the learning strategies used by the pre-service teachers enrolled at the pedagogical formation certificate program in their learning and whether the frequency of using learning strategies varies significantly depending on gender, age, mother and father's education level and the undergraduate program graduated.

\subsection{Problem Statement}

What are the learning strategies used by the pre-service teachers enrolled at the pedagogical formation program in their learning process? And do their learning strategies vary significantly depending on some variables?

\subsubsection{Sub-Problems}

The sub-problems to which answers are sought are as follows;

1) What are the learning strategies used by the students attending the pedagogical formation certificate program in their learning process?

2) Do the learning strategies used by the students attending the pedagogical formation certificate program in their learning process vary significantly depending on gender?

3) Do the learning strategies used by the students attending the pedagogical formation certificate program in their learning process vary significantly depending on age?

4) Do the learning strategies used by the students attending the pedagogical formation certificate program in their learning process vary significantly depending on mother and father's education level?

5) Do the learning strategies used by the students attending the pedagogical formation certificate program in their learning process vary significantly depending on the undergraduate program graduated?

\section{Method}

In this section, the method, model, study group, data collection tools and data analysis techniques of the current study are presented.

\subsection{Research Model}

The current study employed the survey model. The survey model is a research model that aims to describe a past or present situation as it was or is (Karasar, 2012). This model describes a situation as precisely and carefully as possible (Balc1, 2006). In this respect, it was aimed to determine the learning strategies used by the pedagogical formation certificate program students in their learning process.

\subsection{Study Group}

The universe of the current study is comprised of the students enrolled at the pedagogical formation certificate program in the Education Faculty of Burdur Mehmet Akif Ersoy University in the 2015-2016 academic year. The study group on the other hand consists of a total of 271 pedagogical formation certificate program students aged at $20-42$ years old and having graduated from five different undergraduate programs. Of the participating students, $65 \%$ are females $(n=175), 35 \%$ are males $(n=96)$. The programs the students graduated from are as follows: $15 \%$ from mathematics $(n=40), 26 \%$ from administration-public administration $(n=71), 12 \%$ from foreign language $(\mathrm{n}=33), 22 \%$ from physical education $(\mathrm{n}=60)$ and $25 \%$ from philosophy-history $(\mathrm{n}=67)$.

\subsection{Data Collection Tools}

\subsubsection{Learning Strategies Scale}

In order to determine the students' learning strategies, the Learning Strategies Scale developed by Açıkgöz (1996) and revised by Güvenç (2009) was used with permission of the author. The first part of the Learning Strategies Scale has four items to elicit the personal information of the pedagogical formation certificate program students and the second part of the scale consists of two sections having 32 five-point Likert type items collected under five sub-dimensions to determine the students' learning strategy preferences. As a result of the analysis conducted by Güvenç (2009) to determine the reliability of the scale, the Cronbach Alpha coefficient $(\alpha)$ calculated for each sub-dimension is as follows: .85 for the first sub-dimension, .78 for the second sub-dimension, .76 for the third sub-dimension, .74 for the fourth sub-dimension and .72 for the fifth sub-dimension. The Cronbach Alpha coefficient calculated for the whole scale was found to be .91 .

\subsection{Data Analysis}

In the analysis of the collected data, some descriptive techniques; frequencies (f), percentages (\%), arithmetic means ( $\overline{\mathrm{x}}$ ) and standard deviations (ss) in the SPSS 24 program package were used. Parametric t-test was used in the comparison of the variables for which the data were found to be normally distributed while non-parametric 
Kruskal Wallis test was used in the comparison of the variables for which the data were found to be not normally distributed.

\section{Findings and Interpretations}

In this section, findings for each sub-problem are presented. The findings are presented in tables and then interpreted on the basis of the statistical analysis of the data collected with the data collection tools.

\subsection{Findings Related to the First Sub-Problem}

The following findings have been obtained for the first sub-problem "What are the learning strategies used by the students attending the pedagogical formation certificate program in their learning process?"

Table 1. Distribution of the learning strategies

\begin{tabular}{lcccc}
\hline Strategy & $\bar{x}$ & $\mathrm{sd}$ & $\mathrm{n}$ & $\%$ \\
\hline Processing & 3.7 & 6.65670 & 41.1808 & 38 \\
Metacognitive & 3.9 & 3.85145 & 23.6310 & 21 \\
Organization & 3.4 & 5.57732 & 27.3948 & 24 \\
Concentration & 2.8 & 3.51419 & 6.1439 & 12 \\
Memorization & 3.1 & 2.05245 & 13.9520 & 5 \\
General & 3.4 & & & \\
\hline
\end{tabular}

As can be seen in Table 1, the mean distribution scores of the learning strategies are as follows: Processing $(\mathrm{x}=3.7)$, Metacognitive $(\mathrm{x}=3.9)$, Organization $(\mathrm{x}=3.4)$, Concentration $(\mathrm{x}=2.8)$ and Memorization $(\mathrm{x}=3.1)$. Here it is clear that the strategies most commonly used by the students are the metacognitive strategies. The general mean of the students' strategy use is $\mathrm{x}=3.4$. In general, the students use the learning strategies at a medium level.

\subsection{Findings Related to the Second Sub-Problem}

The following findings have been obtained for the second sub-problem "Do the learning strategies used by the students attending the pedagogical formation certificate program in their learning process vary significantly depending on gender?"

Table 2. Results of the t-test conducted to determine whether the use of the learning strategies varies significantly depending on gender

\begin{tabular}{lccccccc}
\hline Strategy & Gender & $\mathrm{n}$ & $\bar{x}$ & $\mathrm{Ss}$ & $\mathrm{sd}$ & $\mathrm{t}$ & $\mathrm{p}$ \\
\hline \multirow{2}{*}{ Processing } & Female & 175 & 41.5886 & 6.67745 & \multirow{2}{*}{ (69 } & \multirow{2}{*}{1.364} & .174 \\
& Male & 96 & 40.4375 & 6.58837 & & & \\
Metacognitive & Female & 175 & 23.9486 & 3.73130 & 269 & 1.841 & .067 \\
& Male & 96 & 23.0521 & 4.01673 & & & \\
Organization & Female & 175 & 28.6514 & 5.19047 & 269 & 5.248 & .000 \\
& Male & 96 & 25.1042 & 5.55448 & & & \\
Concentration & Female & 175 & 13.5714 & 3.03320 & 269 & -2.429 & .016 \\
& Male & 96 & 14.6458 & 4.18262 & & & \\
Memorization & Female & 175 & 6.0343 & 2.05078 & 269 & -1.188 & .236 \\
& Male & 96 & 6.3438 & 2.05107 & & & \\
\hline
\end{tabular}

As can be seen in Table 2, the Processing, Metacognitive and Memorization strategies used by the pedagogical formation certificate program students do not vary significantly depending on gender $(p>0.05)$. Thus, it seems that both the male and female students use these learning strategies similarly. However, the Organization and Concentration strategies were found to be varying significantly depending on gender $(p<0.05)$. The significant difference is in favour of the female students in the Organization strategies while in favour of the male students in the Concentration strategies.

\subsection{Findings Related to the Third Sub-Problem}

The following findings have been obtained for the third sub-problem "Do the learning strategies used by the students attending the pedagogical formation certificate program in their learning process vary significantly depending on age?" 
Table 3. Results of the Kruskal-Wallis H test conducted to determine whether the use of the learning strategies varies significantly depending on age

\begin{tabular}{cccccc}
\hline Age & $\mathrm{N}$ & Mean Rank & $\mathrm{X}^{2}$ & $\mathrm{df}$ & $\mathrm{p}$ \\
\hline 20-25 years old & 189 & 135.05 & & & \\
26-30 years old & 52 & 136.77 & & & \\
31 and over & 30 & 140.63 & .138 & 2 & .934 \\
$\quad$ Total & 271 & & & & \\
\hline
\end{tabular}

As can be seen in Table 3, the learning strategies used by the students do not vary significantly depending on age $(\mathrm{p}=.934>0.05)$. This shows that the frequency of using the learning strategies is similar across the age groups.

\subsection{Findings Related to the Fourth Sub-Problem}

The following findings have been obtained for the fourth sub-problem "Do the learning strategies used by the students attending the pedagogical formation certificate program in their learning process vary significantly depending on mother and father's education level?"

Table 4. Results of the Kruskal-Wallis $\mathrm{H}$ test conducted to determine whether the use of the learning strategies varies significantly depending on mother and father's education level

\begin{tabular}{cccccc}
\hline Education Level & $\mathrm{n}$ & Mean Rank & $\mathrm{X}^{2}$ & $\mathrm{df}$ & $\mathrm{p}$ \\
\hline No Education & 6 & 123.17 & & & \\
Elementary & 123 & 131.37 & & & \\
High school & 76 & 145.68 & 1.771 & 3 & .621 \\
University & 66 & 134.64 & & & \\
\hline
\end{tabular}

As can be seen in Table 4, the learning strategies used by the students do not vary significantly depending on mother and father's education level $(\mathrm{p}=.671>0.05)$. This shows that the frequency of the students' using learning strategies is similar among the students having parents with different levels of education.

\subsection{Findings Related to the Fifth Sub-Problem}

The following findings have been obtained for the fifth sub-problem "Do the learning strategies used by the students attending the pedagogical formation certificate program in their learning process vary significantly depending on the undergraduate program graduated?"

Table 5. Results of the Kruskal-Wallis $\mathrm{H}$ test conducted to determine whether the use of the learning strategies varies significantly depending on the undergraduate program graduated

\begin{tabular}{cccccc}
\hline Programs Graduated & $\mathrm{n}$ & Mean Rank & $\mathrm{X}^{2}$ & $\mathrm{df}$ & $\mathrm{p}$ \\
\hline Mathematics & 40 & 132.55 & & & \\
Administration-Public & 71 & 150.58 & & & \\
Administration & & & & & \\
Foreign language & 33 & 144.23 & 5.470 & 4 & .242 \\
Physical education & 60 & 120.15 & & & \\
Philosophy-History & 67 & 132.75 & & & \\
Total & 271 & & & & \\
\hline
\end{tabular}

As can be seen in Table 5, the learning strategies used by the students do not vary significantly depending on the undergraduate program graduated $(\mathrm{p}=.242>0.05)$. This shows that the frequency of the students' using learning strategies is similar regardless of the undergraduate program they graduated from.

\section{Results, Discussion, and Suggestions}

In this section, results derived from the findings, discussions about these findings and suggestions developed on the basis of the results are presented.

\subsection{Results and Discussion}

The current study was conducted to determine the learning strategies used by the students attending the 
pedagogical formation certificate program in the Education Faculty of Mehmet Akif Ersoy University in their learning process. When the findings obtained in this connection are evaluated, the following results have been elicited:

1) On the basis of the findings obtained for the first sub-question "What are the learning strategies used by the students attending the pedagogical formation certificate program in their learning process?", it can be argued that the students' frequency of using the learning strategies is at the medium level in general. From this, it can be understood that there is no perception developed by the students about the learning strategies yet. This finding is supported by Sucuoğlu and Kete (2011) reporting that the pre-service teachers' frequency of using learning strategies is at the medium level.

2) The findings obtained for the second sub-problem "Do the learning strategies used by the students attending the pedagogical formation certificate program in their learning process vary significantly depending on gender?" have revealed that the Processing, Metacognitive and Memorization strategies used by the students in their learning process do not vary significantly depending on gender. On the other hand, the Concentration and Organization strategies were found to be varying significantly depending on gender. While the significant difference in the Concentration strategies is in favour of the male students, the significant difference in the Organization strategies is in favour of the female students. While the finding of Ural (2006) stating that there is no gender-based significant difference in the learning strategies used by the middle school students supports the finding of the current study, the finding of Taşdemir and Tay (2007) reporting that there is a gender-based significant difference in the learning strategies used by the classroom teachers in favour of the female teachers contradicts with the finding of the current study.

3) The findings obtained for the third sub-problem "Do the learning strategies used by the students attending the pedagogical formation certificate program in their learning process vary significantly depending on age?" have revealed that the learning strategies used by the students do not vary significantly by age. While age has been reported to be a variable significantly affecting many aspects of learning in the literature, in the current study it was found that age does not have a significant influence on the use of learning strategies. This may indicate that the pedagogical formation certificate students' perception of learning strategies has not been fully developed.

4) The findings obtained for the fourth sub-problem "Do the learning strategies used by the students attending the pedagogical formation certificate program in their learning process vary significantly depending on mother and father's education level?" have revealed that the learning strategies used by the students do not vary significantly depending on mother and father's education level. Yet, this finding does not concur with the findings reported by similar studies (Duman, 2008; Ural, 2006).

5) The findings obtained for the fifth sub-problem "Do the learning strategies used by the students attending the pedagogical formation certificate program in their learning process vary significantly depending on the undergraduate program graduated?" have revealed that the learning strategies used by the students do not vary significantly depending on the undergraduate program they graduated from. This finding is parallel to the findings reported by many studies (Bahar \& Sülün, 2011; Demir, 2008; Kahyaoğlu, 2011; Küçükkaragöz, Deniş, Ersoy, \& Karataş, 2008). On the other hand, Şahin and Çakar (2011); in their study conducted on the learning strategies used by education faculty students, found a significant difference in the use of comprehension monitoring strategies between the students attending the department of physical education and the students attending the department of music teaching and in the use of affective strategies between the students attending the department of music teaching and the students attending the department of arts teaching and no significant difference was found in the use of the other learning strategies.

With the developments in information and communication technologies, the information in our lives is undergoing a continuous renewal and change. This change is taking place faster than in previous years in that the telephones that we used 10 years ago can now be seen as antique. This shows that any change can have large effects only in a short-time period. Thus, students need to constantly renew themselves so that they can keep up with new developments. Educational institutions and teachers alone are not enough for students to keep up with this change. Students should be able to create their own knowledge and be aware of how they learn. This means that students should have a good knowledge of how to use and manage learning strategies. As the prospective teachers, pedagogical formation students should also be familiar with learning strategies and use these strategies so that they can serve as a model for their students in their professional lives. In the learning process, students, especially student teachers who will educate future generations, should know what kind of learning strategy is suitable for learning, and should be aware of through which learning strategies they can achieve effective 
learning (Kuzu, Balaman, \& Canpolat, 2014). In this respect, the use of learning strategies is of great importance. In the current study, it was aimed to determine the learning strategies used by the pedagogical formation certificate students and whether these strategies vary significantly depending on some variables. On the basis of the findings of the current study, it can be argued that the students' perception of learning strategies has not been fully developed and that they use the learning strategies at a medium level in general. This may indicate that the students performed their previous and current learning activities with a weak awareness of learning strategies. In a globalizing world, individuals who use information and construct information themselves are required. In this respect, learning strategies should be imparted to students at all levels of our educational institutions and their awareness of learning strategies should be raised.

\subsection{Suggestions}

In light of the research findings, the following suggestions can be made.

1) The effect of learning strategies on learning and academic achievement can be investigated.

2) Research should be conducted on the determination of learning strategies at early ages.

3) The effect of parental support on the use of learning strategies should be investigated.

4) Detailed investigations should be conducted on students' homeworks.

5) Similar studies can be conducted on students from different grade levels of education faculties.

6) Teachers and parents should be trained on learning strategies.

\section{References}

Açıkgöz, K. (2007). Effective learning and teaching (7th ed.). İzmir: Biliş yayınları.

Bahar, H. H., \& Sülün, A. (2011). Pre-service science teachers' learning styles, the relationship between gender and learning style and academic achievement according to learning style. Kastamonu Education Journal, 19(2), 379-386.

Balc1, A. (2015). Methods, Techniques and Principles in Social Sciences (11th ed.). Ankara: Pegem Akademi.

Beyaztaş, D. İ., \& Senemoğlu, N. (2015). Learning approaches of successful students and factors affecting learning approaches. Education and Science, 40(179), 193-216. https://doi.org/10.15390/EB.2015.4214

Çalışkan, M., \& Sünbül, A. M. (2011). The effect of learning strategies instruction on executive cognitive knowledge, the use of executive cognitive skills and achievement (the case of elementary school 6th grade Turkish course). Educational Sciences in Theory and Practice, 11(1), 133-153.

Çelik, D. (2016). The relationship between the 11th grade students' thinking styles, learning strategies and thinking styles and learning strategies (Unpublished master's thesis). Pamukkale University Educational Sciences Institute, Denizli.

Demir, T. (2008). Learning styles of the students from the Department of Turkish Teaching and their relationships with different variables (The case of Gazi University). International Social Research Journal, 1(4), 129-148.

Duman, B. (2008). Comparison of the educational philosophies adopted by students and the learning styles and strategies they use. Ç.Ü. Social Studies Institute Journal, 17(1), 203-224.

Efe, N., Sağırlı, M. Ö., \& Ünlü, İ. (2009). Investigation of learning strategies in relation to some variables. Erzincan Education Faculty Journal, 11(2), 227-238.

Erdem, A. R. (2005). Effective ways in learning: Learning strategies and their instruction. Elementary school-Online, 4(1), 1-6.

Erden, M. (1997). Importance and type of the information in an explanatory text on the recall of this information. Hacettepe University Education Faculty Journal, 9, 173-192.

Güven, M. (2004). The relationship between learning styles and learning strategies. Eskişehir: Anadolu University Education Publications.

Güvenç, H. (2009). The Effect of Study Journals on the Students' Use of Self-regulated Learning Strategies. Çanakkale Onsekiz Mart University. TUBİTAK Project No: 107K386

Karakış, Ö., \& Çelenk, S. (2007). The general level of learning strategy use of students from different departments of education faculties: The case of A.G̈.B.Ü. Abant İzet Baysal University Education Faculty Journal, 7(1), 26-46. 
Karasar, N. (2012). Scientific research methods. Ankara: Nobel Yayınları.

Kete, R., \& Sucuoğlu, H. (2011). The learning strategies used by the pre-service biology and science teachers (The case of DEÜ). Elementary Education Online, 10(1), 230-243.

Küçükkaragöz, H., Deniş, H., Ersoy, E., \& Karataş, E. (2009). Investigation of the learning styles and problem solving skills of pre-service math, science, Turkish teachers. The First International Congress of Educational Research May 1-3. Educational Research Association. Çanakkale 18 Mart University.

Kuzu, S., Balaman, F., \& Canpolat, M., (2014). Determination of the education faculty students' learning strategies and their comparison across the departments. Education and Instruction Research Journal, 3(2), 257-264.

Özer, B. (2001). Learning strategies in the elementary and middle school curriculums. Educational Sciences and Application, 1, 17-32.

Şahin, H., \& Çakar, E. (2011). The effect of the education faculty students' learning strategies and academic motivation level on their academic achievement. Turkish Educational Sciences Journal, 9(3), 519-540.

Şahin, H., \& Uyar, M. (2013). Reflections of the use of learning strategies on academic achievement. Abant İzzet Baysal University Education Faculty Journal, 13(1), 164-177.

Senemoğlu, N. (2005). Development, learning and teaching (12th ed.). Ankara: Gazi Kitabevi.

Şimşek, A. (2006). Teaching of cognitive strategies, teaching based on content types (1st ed.). Ali Şimşek (Ed.). Ankara: Nobel Yayın Dağıtımı.

Sönmez, B., Gündüz, G. F., \& Selvi, K. (2015). Adaptation of the ACRA-shortened learning strategies scale to high school students: validity and reliability analysis. Elementary Education Online, 14(4), 1241-1259.

Sucuoğlu, H. (2003). The effect of the cooperative learning on students' attribution, acquisition and strategy use (Unpublished doctoral thesis). Dokuz Eylül University Educational Sciences Institute, İzmir.

Taşç1, G., Altun, A., \& Soran, H. (2008). A qualitative study on the determination of the pre-service biology teachers' learning strategies. Hacettepe University Education Faculty Journal, 35, 284-296.

Taşdemir, A., \& Tay, B. (2007). The effect of the pre-service science teachers' using learning strategies on academic achievement. Education Faculty Journal, XX(1), 173-187.

Tay, B., \& Yaygin, B. (2008). The learning strategies used by the 4th grade students in the classroom environment in social studies classes. Ahi Evran University Kirşehir Education Faculty Journal (KEFAD), 9(3), 73-88.

Tezbaşaran, A. A. (1997). Effective learning and teaching for thinking, discussing, solution producing society and computer-based information technologies. Science Technical Journal, 355, 52-57.

Toy, Ö. (2007). Relationships between the learning strategies used in the biology course and achievement motivation (Unpublished master's thesis). Dokuz Eylül University, İzmir

Ural, M. (2006). Middle school students' learning and studying strategies (The case of the city of Nevsehir) (Unpublished master's thesis). Erciyes University Social Sciences Institute, Kayseri.

Vural, L. (2011). Learning problems experienced by pre-service teachers in their works and learning strategies. Dicle University Ziya Gökalp Education Faculty Journal, 16, 46-65.

Yavuzarslan, M. (2017). Investigation of the self-regulated learning strategies of the students from the department of computer and instructional technologies (Unpublished master's thesis). Yeditepe University Educational Sciences Institute, İstanbul.

YÖK. (2016). Higher Education Council. Retrieved from https://www.yok.gov.tr

Yücel, T. (2012). Learning strategies used in the solution of the problems in the unit of electricity in our life in the Science and Technology Curriculum (Unpublished master's thesis). Ahi Evran University Social Sciences Institute, Kırşehir.

\section{Note}

Note 1. This study is derived from a research conducted for the seminar course at the graduate level. 


\section{Copyrights}

Copyright for this article is retained by the author(s), with first publication rights granted to the journal.

This is an open-access article distributed under the terms and conditions of the Creative Commons Attribution license (http://creativecommons.org/licenses/by/4.0/). 